\title{
Scourge of Internal Displacement of Afghan Refugees: Compromised Resiliency
}

\author{
Mussarat Jabeen ${ }^{1, *}$, Venkat Pulla ${ }^{2}$ \\ ${ }^{1}$ Department of IR \& Pol Science, University of Sargodha, Pakistan \\ ${ }^{2}$ Senior Lecturer, School of Social Sciences, University of the Sunshine Coast, Maroochydore, Qld, Australia \\ *Corresponding Author: mjabeenasif@yahoo.com
}

\begin{abstract}
Internal displacements stand out as a major human rights issue in South Asia. The governments in the region find it already hard to cope up with these crucial issues and simultaneously to deal with border security and internal social security issues. These Internally displaced people (IDPs) have lead despondent existence in their environments with restricted provisions and possessions at their disposal. Not having enough skills to compete with the local populations marks their sagas of coping with exploitation with compromised resiliency. Life does not cease but becomes vulnerable evidently letting the people to remain in abject poverty (Pulla, 2012). To address the destitution of IDPs, we argue that mitigation strategies with a human rights' perspective are required and that such perspectives do not sit within the capacity of some of the South Asian countries particularly that of Afghanistan and its immediate neighbor Pakistan. The paper explores the causes, problems and opportunities suggesting options of reintegration and repatriation on their return for including them in the mainstream.
\end{abstract}

Keywords Displaced Persons, Camps, Violence, War, Military Troops, Rehabilitation, Security and Humanitarian Aid

\section{Introduction}

In Afghanistan, internal displacement is such a pervasive and long-lasting phenomenon that 76 per cent of its population has to pass through this experience (ICRC, 2009). In June 2012, it was officially estimated that more than 400,000 people were displaced but this number did not cover all those persons, which were displaced by natural disasters and wide-spread human rights abuse. The figure of IDPs is growing gradually, reflecting the continuing rise in insecurity across large swathes of the country. Displacement leads to a range of serious protection challenges, including threats to life and freedom of movement. National and international responses are substantial, but they have not consistently been rights-based. It is observed that in numerous cases, only IDPs who meet official criteria for registration are eligible for food assistance and other necessary services. In the case of Afghanistan Pulla wrote in the 'insight into conflict, September, 18, 2012.

'I think a need to also look at the impoverishment and precarious living of internally displaced people (IDPIs) within this region. This as an issue is left to national governments who already have enough on their plate to deal with questions relating to border security and have tendency not to worry too much about the declassed movement of people from pastoral and rural occupations from the border villages to more interiors of these very conflict centered nations. These IDPIs often do not have enough skills to compete and lead a life in their new environments and continue to remain a second priority within their own country. Addressing IDPIs impoverishment, I argue also requires mitigation strategies from a human rights perspective. Life does not cease but is made vulnerable evidently allowing people to remain in abject poverty. I am of the opinion this is already a systemic violation of human rights. I think we need a concerted effort that the focuses on internally displaced persons as well IDPs in all these six nations, Afghanistan, India, Pakistan, Bangladesh, Bhutan and Nepal and a sensitive approach of dealing with their impoverishment comparable to the refugees (Pulla, 2012, Sept,18).

Definitions of Displaced Persons and Refugees

It is estimated that two thirds of the IDPs outside camps live below the poverty line and do not have adequate access to food, housing and basic services. As a World Bank-UNHCR study of 2011 exposed that urban IDPs are 'more vulnerable and worse-off than the non-displaced urban poor' who face issues like unemployment, insufficient 
housing and food insecurity. In addition the IDPs are also facing threats of disability, forced labour and child labour. Single females whose resources and coping abilities are restricted by traditional codes of social seclusion continue to live insecure lives. Increasing numbers of IDPs have found themselves in protracted displacement as conflict and violence persisted. Prospects of returning to their homes are also limited by their deprivation of land and inability to recover property as no social support mechanisms are at their disposal.

As defined by international treaties and accords, "Internally Displaced Persons are persons or groups who have been forced or obliged to flee or leave their homes or places of habitual residence, in particular as a result of or in order to avoid the effects of armed conflict, situations of generalized violence, violations of human rights or human-made disasters, whenever the responsible State or defacto authority fails, for reasons that violate fundamental human rights, to protect or assist those victims and who have not crossed an internationally recognized State border" (UN Guiding Principles, 1998). This internal displacement makes the people vulnerable forcing them to live in camps where basic necessities are appallingly inadequate. IDPs legally remain under the protection of their government even though this government may be the cause of their flight as well as eligible for retaining their rights as citizens for protection in terms of international humanitarian laws and human rights. Following are a few factors that are likely to increase the need for protection: Internally displaced persons may be in transit from one place to another, may be in hiding, may be forced toward unhealthy or inhospitable environments, or face other circumstances that make them vulnerable.

In comparison a refugee is an individual who has "owing to well-founded fear of being persecuted for reasons of race, religion, nationality, membership in particular social group or political opinion, is outside the country of his nationality and is unable or, owing to such fear, is unwilling to avail himself of the protection of that country; or who, not having a nationality and being outside the country of his former habitual residence as a result of such events, is unable or owing to such fear, is unwilling to return to it" (The 1967Protocol, UNHCR, 2013). After the World War II, displaced persons and refugees were high on the international agenda. In 1946, recognizing the urgency of the problem, the United Nations' General Assembly added the cardinal principle that "no refugees or displaced persons who have finally and definitely, in complete freedom, and after receiving the full knowledge of the facts including adequate information from the governments of their countries of origin, expressed valid objections to returning to their countries of origin [...] shall be compelled to return to their country of origin. The future of such refugees or displaced persons shall become the concern of whatever international body may be recognized or established (as a result of the deliberation of the special committee)" (Zieck, 1997, p. 48). This principle was added to assist and encourage the displaced persons to return to their country of origin. Those who were not ready for repatriation despite the changing situation were taken as 'war criminal, traitors, collaborators, quislings and anti-democratic elements who should be returned to their country for judgment' (Ibid).

Assessing the need to clearly define the eligible persons for international assistance, the UN established a special agency named International Organization for Refugees in 1946 (Holborn, 1956). The IOR was to provide protection and facilitation to refugees. But it stopped working as its task was expensive and because of the politics of the Cold War. It was replaced by the UNHCR in 1950 and paved the path for the 1951 Refugees Convention. Later, the 1967 Protocol applied the same definition but removed both, the date first January 1951 and the geographical restriction. The Protocol was enforced on October 4, 1967. The following are the additional factors that demonstrate the situation of the Afghan IDPs. They include:

- Children, the elderly persons, or pregnant women who experience profound psychosocial distress related to displacement

- People removed from their sources of income and livelihood adding to their physical and psychosocial vulnerability

- Disrupted schooling in children and adolescents generating frustration

- Men and women who have been abused by armed combatants, or forced into the conflict by other parties. They also lack the necessary identity documents essential to receiving benefits or legal recognition (IDMC, 2013).

The depth and magnitude of IDPs problems need to be viewed from the perspective that their number surpasses that of the refugees by two to one, and they are more miserable as compared to refugees. The UNHCR estimated that 26.4 million internally displaced persons are living throughout the world, higher in number than that of the refugees (Skreli, 2013). Only the Democratic Republic of Congo has 1.8 million IDPs (Kalumiya, 2001). It is observed that the governments responsible for securing the rights and well-being of IDPs are themselves responsible for their plight, as occasionally they pursue such strategies, which aim to change the ethnic ratio or gaining control over economic resources. Repression and catastrophe also force people to flee from their homelands.

\section{Afghan Displaced Persons and Refugees}

It is an acknowledged fact that the dividing line between forced and voluntary displacement is indiscernible. This is especially the case in war-torn Afghanistan, where conflicts and security concerns force the people to move out of places and to seek refuge in some other place. Movement from rural to urban locations in pursuance of safety and economic opportunities is common. Their access route points to 
neighboring Pakistan due to porous border. The frontiers between Afghanistan and Pakistan known as the Durand Line were officially demarcated in 1893. But this line is apparent on printed maps rather than on the ground since the population living on either side actually share common origins, tribal heritage and culture. The people continued crossing the borders as needed and never treated it as the boundary line between the two countries. They act as if it did not exit, crossing freely from one side to another. The tribes living on one side of the border have their relatives and wage earning jobs, on the other. Owing to the vague delineation, the governments never demanded entry papers from local people at the formal border crossing prior to the terrorist attacks of 9/11. Before the eruption of wars, the populations of border areas were used to cross the line daily for working on the other side. The war has not changed this status and communities on both sides still have economic and social links blurring the boundary line rather than strengthening it. Keeping this perspective in view, the Afghan refugees and IDPS are viewed as one category labeled as displaced persons in this paper. Either they are living in Afghanistan as internally displaced persons (IDPs) or as refugees in the border areas of Pakistan.

\section{Conflicts in Afghanistan}

Three decades of war and continued violence in Afghanistan have forced 40 percent of the population to leave their homes at least one time while 17 percent have been displaced twice, internally and externally for security concerns (ICRC, 2009; Oxfam, 2009). In 1990s, the conflict was at its peak and about 7.5 million people were displaced. Among them, 3.2 million took refuge in Pakistan while Iran hosted 2.35 million refugees and approximately two million were internally displaced (Knowles, 1992). After Soviet withdrawal in 1989 , about 1.5 million refugees returned to Afghanistan but continued civil war (1992-1994), the emergence of the Taliban (1994) and three years of drought brought a second wave of internal displacement forcing the people to migrate to the neighboring areas (UNHCR, 1997). Before 9/11, there were about 1.2 million IDPs and approximately five million refugees. After the fall of the Taliban, huge number of these people returned to their places of origin but resumption of conflict between governmental forces and insurgents led to the new wave of internal displacement (UNHCR Country Operations Profile, 2011; WB/UNHCR, 2011).

All warring parties including Afghan forces, non-state armed groups and International Security Assistance Forces (ISAF) have accelerated and contributed to the displacement (BI/NRC, 2010). Military operations against the remnants of Al-Qaeda and the Taliban regime by the Afghan security forces and international armed forces also forced a huge number of victimized groups to leave their places in the south, particularly during the operation of 2010/11, when the number was increased and more international troops were deployed (Rizvi, 2011)

About 5.7 million displaced persons have voluntarily repatriated to different areas in Afghanistan during the last 10 years. Among these persons, more than 4.6 million were assisted by UNHCR. There are still 1.7 million registered refugees in Pakistan and one million in Iran (UNHCR, 2013). In May 2013, Afghanistan, Iran and Pakistan along with donors and UNHCR prepared a 'Solutions Strategy, for Afghan refugees to support their voluntary repatriation and sustainable reintegration and assistance to host countries' during an international conference in Geneva. It was aimed to be community based development and capacity building measures securing places of refuge for victims in neighboring states with the objectives of repatriation and reintegration in their country of origin. Displacement in Afghanistan has occurred due to military conflicts, although there have been environmental causes such as natural disasters internal targeted persecution, intimidation, extortions, land disputes, night searches, aerial attacks, illegal taxation, forced recruitment and inter-tribal disputes have also caused the displacement. The task to estimate IDPs is a complex which exacerbates any targeted humanitarian assistance (IDMC, 2013).

The intensity of military operations in the North and Western regions increased conflict-induced displacement in Ghor, Faryab, Badghis, Herat, Jawzjan and Balkh provinces during the last three years (UNHCR, 2012 ; IDMC, 2013). Since 2012, the Western, Eastern and Southern regions have been witnessing an increase in conflict-induced internal displacement. The armed conflict and prevailing insecurity have also accelerated displacements from less insecure Central and Northern regions (Afghanistan Annual Report 2012). It is also noted that the number of people fleeing from Northern and Western areas is more than double in 2011. In the West, 'preventative flight' in anticipation of persecution is common. This type of displacement is very difficult to trace, as the individuals or families move by themselves. They often stay with host families during the displacement (Schmeid, Mundt and Miszak, 2010).

In addition to conflicts, migration has also been a "coerced" strategy in Afghanistan owing to natural disasters. The dry climate, rugged terrain and dependence on rain-fed agriculture make it prone to drought. The multi-year droughts and fluctuations in agricultural production in the past decade has further complicated the lives of IDPs and "forced out" them to urban areas for better economic opportunities. According to a report of NRVA of 13 August, 2007, "one in four households living in rural areas has had at least one seasonal migrant over the past year, or (at least) one member who migrated for economic motives over the past five years or who has permanently moved away in search of better economic opportunities" (WB, 2012).

\section{Displaced Persons}

Displacement is becoming increasingly prolonged and 
problematic for the Afghans due to the intensity of the conflict and often entrenched positions of the warring parties. Absence of basic needs and critical services in places of refuge with severe weather conditions are deteriorating the protection positions of already vulnerable groups. For IDPs, national and international responses have been largely insufficient as they face physical threats and mobilization barriers on a larger scale. They have to face inadequate food and water, inhospitable environment with security threats, inappropriate living places, and above all unemployment. Those who seek shelter in urban settings are exposed to discrimination and are marginalized and continue to be more vulnerable than the permanently existing urban poor in those locations (UNHCR, 2012).

In recent years, problem of reintegration and settlement is intensifying as huge numbers of refugees are repatriating and it has become difficult for them to trace their old houses or return to areas of origin (WB/UNHCR, 2011). The majority of them have been deprived of their ancestral properties due to the absence of legal documents (UNHCR, 2012). Lack of employment resulting in near starvation for those who have returned to their native places has become a major issue. Reports of such happenings increase the resolve of others not to return to their native areas and force content with a marginalized existence in neighborhood countries. This is a concern of serious ramifications for the Afghan government, humanitarian agencies and to the local poor in the neighboring countries where these IDPs intend to be settled. Return and reintegration of refugees and IDPs is increasingly becoming difficult as a majority that moved to the fringes of urban or semi-urban areas is not ready for repatriation. Simultaneously cities like Kabul, the capital, have doubled its population during the last decade. From 1.78 million in 1999, it has moved to 2.9 million in 2010. Other cities including Kandahar, Herat and Khost have experienced the similar increase (Afghan Refugees, 2012). Overcrowded cities and meager resources account for the reluctance to repatriate. This hints to a more catastrophic scenario where a large segment of IDPs is at risk failing to settle in their places of origin due to inhospitable circumstances (IDMC, 2013).

Currently the dilemma is, should they remain where they sought refuge or return to their native areas. Mustafa, a refugee, shares his grievances as follows:

"We are in a bad condition here. Ten children died of respiratory diseases during the past winter in our neighborhood. The winter is here again and most of our children are sick” (IRIN, 2013). Mustafa's family of 10-members had to move from Jalalabad in Nangahar Province from a bus station where reconstruction work started and swallowed their shelter. Jalalabad has 68,432 registered IDPs, which is next only to Herat (Ibid).

Another refugee is Ahmed, a 19 year old polio victim who came from Afghanistan nine years ago. He too has to return with other refugees. He shared his apprehensions for the internal situation of Afghanistan. According to him, when he went to his native town in the Northern Afghanistan, it was difficult to find necessary medications for his ailments. His father was unable to find work and the disappointed family decided to return back to Pakistan after spending only five turbulent months in Afghanistan. They returned to refugee camps in Peshawar where medical treatment and other facilities had been arranged by the UNHCR and other humanitarian agencies.

There are also problems in delivering the assistance in Afghanistan effectively. It is limited due to the lack of access of humanitarian agencies to several IDPs locations. Thus their needs of livelihoods, education and health care remain unfulfilled. In April 2008, a National IDP Task Force was formed to develop a framework for a 'coordinated response to IDP needs.' This body was a joint project of UNHCR and Ministry of Refugees and Repatriation (MoRR) including other humanitarian agencies of the UN, NGOs, friendly governments and donor agencies. The Task Force was aimed to build a "comprehensive and coordinated understanding of the number, profile, location and protection and assistance needs of IDPs; and to coordinate responses with the objective of providing sustainable and durable solutions." The emphasis of UNHCR is on war-ridden displacement showing concern for the protection of those persons who are displaced by natural calamities along with supporting the work of other agencies of the UN and IDP Task Force (UNHCR, 2008).

It is noteworthy that a huge number of IDPs settled in urban centers is a result of secondary displacement. In the years of 2012, the ratio of internal displacement remained high against a backdrop of continuing armed conflict with increased civilian casualties at the hands of non-state armed groups and inescapable conflict-related violence. The air strikes and night raids also destroyed houses and agricultural land, fuelling displacement across the country (AI, 2012, p. 18). It was reported that the atrocities and abuses of the Afghan Local Police also led to displacement in the North and Uruzgan province in the South (HRW, 2011; TLO/NRC, 2011). Discussing the reasons, Ewen Macleod, UNHCR country representative for Afghanistan stated that growing insecurity is coinciding with drought and high rates of fuel and food forcing the people to move toward the cities, burdening the urban economy (Majidi, 2011).

\section{Secondary Displacements}

Absence of basic security, insufficient community services, lack of livelihoods, natural disasters and food shortage are leading to urban displacements in Afghanistan, which is referred to as 'secondary displacement'. The available arrangements for shelter and infrastructure are insufficient as only less than half returning refugee families are able to live in suitable dwellings. Another problem is the 
identification of DPs in urban areas from the urban poor by the humanitarian agencies. The IDPs remain scattered across Afghan towns and cities where they face deplorable conditions having no access to donors or aid agencies. This problem is highlighted by several studies (UNHCR, 2013).

Nassim Majidi, a consultant to Samuel Hall of Norwegian Refugee Council (NRC), told the Integrated Regional Information Networks (IRIN, 2013) that:

"The problem at this stage is that the government talks about returns and the IDPs about settling, so there is an expectation gap. Some of the assumptions that are still common are that displacement is a temporary state. We found that vulnerability doesn't diminish as people stay for several years, and sometimes people even become more vulnerable."

Bo Schack, UNHCR representative, comments:

"When it comes to a long-term solution, we are talking about people in their own country and it's their choice where to live" (Ibid).

Many IDPs are at continuing risk due to threatening environment for physical security and safety, including extortion and oppression, which is the main cause of secondary displacement. Gender specific discriminations and challenges are also there to face. Allegation of support for conflict parties is common. The male DPs are at risk of forced recruitment or have been accused of being in association with warring parties. Displaced women and children are in a more disadvantageous position. Traditionally, women in Afghanistan are more dependent on their male counterparts; as such they are easy targets for heinous exploitation including forced marriages to local power brokers and as bonded sex slaves. The single female headed families or single women face problems as they are denied or have limited access to jobs and basic social services. The tradition of hijaab or the veil further complicates their problems and is a hurdle to their access to the field workers of donor agencies who are mostly male. There are legal provisions to protect their rights but in paper only as Navi Pillay, UN High Commissioner for Human Rights says:

"Judges, prosecutors and police in many parts of Afghanistan have begun to use the new law, which is a positive development, but unfortunately only in a small percentage of violence against women cases... Although the law's implementation is clearly growing, there is a very long way to go before Afghan women are fully protected from violence and their equality is properly upheld through this important law" (UN News, 2012).

The displaced children on the other hand are exposed to child labour and forced recruitment for the warlords and this practice is more common among the separated children. Apart from these abusive practices, children are also at the risk of sexual violence and trafficking. The denial of access to educational facilities to the children of displaced families is far-cry because they cannot afford schooling owing to economic constraints. (UNAMA, 2013).

The remaining network of land mines and explosive devices of Soviet troops are still a source of trouble to the DPs trying to settle in unacquainted areas. Others are restricted access to water, shelter, cultivated land and meadows in their former places, which becomes a hurdle to their resettlement and which also impedes the restoration of essential infrastructure. Further, the annihilation of cultivated fields, houses and properties by the bombardments directly hamper the capacity of displaced persons for voluntary return and to resume living in their native places.

The mobilization of DPs from one place to another is not free from risk. It is noteworthy that there are security threats when shifting from their native places to safe locations. They have to encounter various checkpoints which levy so called taxes and slow down their movements along with threats to their lives. Some complaints have been made that this practice delayed movement and prevented emergency medical assistance for the DPs, with not much encouraging consequences. In one such incident in Central area, four out of the seven seriously injured men succumbed to their injuries when their vehicle was stopped at one of the check points erected by the local warlords. Some incidents were reported when a group of DPs was trapped in a remote location due to the ongoing conflict; the DPs remained inaccessible to the assistance agencies and thus were helpless for days at a stretch.

\section{Hurdles in the Path of Resettlement}

A complex array of political, security and socioeconomic factors have contributed to the gradual decline in the number of refugees returning from the neighbouring countries to Afghanistan. It is also believed that in the wake of the withdrawal of foreign troops in 2014, internal security situation would further worsen and risks of displacement would occur hampering the process of repatriation of IDPs to their habitats (Schmeid at al., 2010). In the post withdrawal scenario, the vacuum created by the foreign troops would be filled by an inefficient Afghan force, which would not be accompanied by a transitional mechanism for stability and, which would allow the Taliban forces and other loyalists to turn to their tribes rather than to the central authority, thus setting a perfect scene for the Taliban's resurgence. The resurgence, if successful, is expected to be more administratively expensive and is more likely to eject more Afghan DPs as they are more vulnerable to terrorist acts than the people living in their native places (Dawn, 2012, December 15). According to an analyst, "it is now a good time to get the policies in place to facilitate integration and to change the discourse on internal displacement because the numbers will only increase in the coming years" (IRIN, 2013). The effects of withdrawal are compounded by natural disasters that have made it difficult to differentiate between the two types of displacements (OCHA, 2012). Armed 
conflict has also intensified the internal disputes causing additional displacement. Above all, integration is not received well by the local authorities, due to paucity of resources and existing overcrowded living places. Abdul Samad Hami, deputy minister of the Afghan Ministry of Refugees and Returnees (MoRR) said:

"We've spoken with mayors and
municipal leaders and no-one wants to
integrate IDPs. They say they are spoiling
the community or the land and need to go.
We're trying to change the discourse on
internal displacement because the numbers
will only increase in the coming years"
(IRIN, 2013).

According to the reported data, ten provinces are at the top of the list for hosting IDPs. Kandahar and Helmand are protecting the 11 and 14 per cent of IDPs respectively. Uruzgan and Zabul have four and three percent displaced persons. The West is second to Herat providing shelter to 16 percent. Ghor is in the seventh position providing refuge to four per cent. The East is hosting 16 percent of conflict-induced persons while Kunar, Faryab and Ghazni are also providing shelter (UNHCR, 2012).

In the past, the government remained reluctant to take initiatives for developing infrastructures in temporary camps or camp-like residences of the refuge-seekers in urban areas. It was assumed that camp sites with lower infrastructures would discourage the DPs to make urban slum areas as their permanent residences. The option of integration requires the acceptance that the status of DPs is no longer temporary and requires long-term strategies of providing services, economic opportunities and housing on a permanent basis rather than the existing short-term humanitarian aid centered program philosophy.

\section{Impacts of Conflict on Displaced Persons}

The ongoing conflict has disturbed the lives of IDPs directly making them homeless and shaping migration movements within Afghanistan. Before the war, rural Afghans earned their livelihood from agriculture but they lost it and others abandoned it due to migration to the refugee camp sites for protection and safety. According to a study, the conflict destroyed urban assets and paralyzed the rural economy including irrigation system, roads, markets and commercial centers (Altai, 2006). It would take long time to accomplish the pre-conflict position. In the current situation, the flawed economy is unable to merge huge number of refugees. Moreover DPs prefer to settle in economically viable and dynamic urban areas to resume better livelihood strategies.

Owing to internal insecurity, a large number of DPs are in fear of losing their pre-conflict livelihood arrangements and pieces of land. This notion is further strengthened by the experiences of those persons who have had to pass through the secondary displacement. Several studies have shared the stories of the returnees who were unable to manage financial matters in their places of origin and failed to gain access to their land and property due to the destruction of homes, land records and identification documents. Our interviews of displaced persons in border areas of Pakistan revealed that a number of them who did visit their land of origin found that their friends and relatives had no jobs in their places of origin and hence returned to the border area camps. Another group stated that they were happy as refugees in Iran, but on returning, they faced financial problems in their original homes and ultimately moved to other cities in search of a better livelihood. No doubt, there are a few cases of successful resettlement that were the result of newly acquired skills and capital, gained during the exile in the neighboring countries but this number is considered very low. Here are the questions being raised regarding the financial burden of fulfilling the basic needs of these asylum seekers. A country like Pakistan is already overpopulated with an impoverished economy and is not in the position to accommodate such a large number of DPs despite the fact that the international community is sharing the burden of refugee camps but a permanent camp-life is not the solution to displacement.

Another issue relates to the asylum structure and policy is the belief that it would be temporary and that most of the people would return back to their homes. The neighboring countries provided shelter to DPs with hope of their repatriation but thousands of them are not willing to return their own country. Human Rights critics consider this as an abuse of asylum norms, making the states to restrict their border control. Additionally, there are concerns with regard to security as many neighboring nations follow strict admission policies, which warrant the risks of asylum seekers resorting to illegal entry. To add fuel to their miseries, the media portrays these dejected persons as criminals. There is also a growing concern that they will become involved in trafficking, drugs and arms trading. Lack of economic incentive for the states providing refuge, is increasing their domestic economic pressure. In case of low resources, no country can provide a 'proper sufficiently solid durable basis for refugee protection.' The generosity of the UN for displaced persons is insufficient as its agency UNHCR alone is incapable of managing them.

The continued impacts of conflict on economic and security conditions are causing displacements forcing people to leave their communities. Simultaneously there is also a movement of people from the rural to the urban areas in search of better livelihood opportunities. Such migrations exacerbate the situations making it difficult to distinguish between the two types of migration; migration due to conflict and migration due to lack of livelihood. These differences between voluntary migration and forced displacement carry equal risks and provide new sets of difficulties with regards to assistance particularly when it comes to urban areas. The 
IDPs tend to set up homes in informal settlements and merge with the urban poor and compete with the existing urban poor for access to economic aid, land, shelter, water, food and other job-earning opportunities. DPs in rural camps, or protracted DPs are easy to identify but urban DPs are not easy to separate owing to the environment in which they live. Consequently, they are often less 'visible and recognizable' and no criteria can be determined when displacement formally ends (Schmeid at al., 2010).

\section{Closing of Refugees Camps in Pakistan}

Pakistan has been supporting the one of the largest refugee movements in recent history for thirty years but increasing security, political, social and economic challenges are forcing Pakistan to repatriate these guests as peace is established in their homeland. Hundreds of thousands of Afghans are in tension due to the threat of deportation back to their country as the government of Pakistan has fixed $30^{\text {th }}$ of June 2013. The repartition deadline will be extended but the long term position of Afghan refugees in Pakistan remains uncertain (Express Tribune, 2013, June 4). These persons have no option but to return to their homes. Three camps are installed for voluntarily repatriation and a stipend of US\$150 is fixed for each person before his return to Afghanistan (Aaj 2012, September 25). However, displaced persons are not prepared to leave the camps citing insecurity, lack of shelter and jobs, while the international community is also criticizing Pakistan for throwing them back into a war-torn country thus enhancing their problems. These persons are blaming both countries, Pakistan for forcing them to leave and the Afghan government for stringing them with failed promises.

Approximately 1.7 million registered and unregistered refugees are still living in Khyber Pakhtunkhwa, Northwest province of Pakistan, facing the imminent prospect of removal while the Afghan government is showing concerns for huge number of jobless and impoverished persons into a country where livelihood and shelter is already in scarcity. The spokesman of the Afghan Refugee Ministry, Islamuddin Jurat admitted that there was a "small problem" in KP showing his satisfaction on Pakistan's consent for giving the Afghans "some legal status to stay there" (Dawn 2012, June 25). A few groups in Pakistan blame illegal Afghans for involvement in crime but such accusations are just excuses to get rid of these asylum seekers. An official stated, "Afghanistan doesn't have the capacity to absorb so many people. It doesn't have the resources in terms of schools, clinics and especially jobs." Pakistan as the host of a huge number of refugees has made several decisions and policies as well as built camps in border areas. But the bottom line is that Pakistan has serious consequences for this gesture of kindness. These refugees have alarming effects on economic, political and social values as well security related concerns. The UNHCR called Afghanistan as the world's biggest producer of refugees (CRS, June 2006).

\section{Conclusions}

The problems of DPs demand to be resolved on priority basis and protection as its main objective. It is observed that the vast majority of DPs are not willing to return to their places of origin. Here UNHCR's recommendations can be analyzed recommending three solutions to the refugee problems throughout the world. First is repatriation of refugees to their places of origins second is their integration into the states where they had taken refuge and the third is their resettlement to a third state. If the options mentioned above are analyzed, under the lenses of Afghan refugees, following conclusions can be attained.

The case of resettlement in the host countries; Pakistan and Iran have been under pressure owing to the already existing overpopulation and underdevelopment in these states. In case of Pakistan, the Pathans from tribal areas or even KP may show readiness to accommodate their Afghani brothers due to their family ties with them. However, these tribal areas of Pakistan are among the least developed areas and thus the resettlement of the Afghans in these areas may not work well and may soon cause another wave of internal displacement for which the mainstream Pakistani society is quite reluctant to accept these Afghans in urban areas. In Karachi, for instance, illegal immigrants from Afghanistan have become an anomaly and the administration of this metropolitan is unable to cope with the demographic challenges increasing due to this migration.

The resettlement of Afghan refugee into a third state is likely to be very gigantic and perhaps less likely to be applied covering a large mass of refugees. On the economic front, the global economic slump is a hurdle in the accommodation of hundreds of thousands of Afghans into a third state. The Gulf countries that were the main recipients of Afghan workers after the Soviet invasion, are now unable to repeat their generosity and some of them (Saudi Arabia for instance) are even in the process of repatriating the already existing immigrants. Second is the political concern which is shared by the Western states. The Afghans are simply being considered as akin to the Taliban or terrorists for that matter. Thus, it is very difficult to imagine that the Afghan refugees will be accepted and integrated by Western states like Canada or Australia except in small numbers. The cultural incompatibility in the West is another hindrance in this path to settlement. So, while the current host states are unable to integrate the Afghan refugees, the third states are incapable or unwilling to accommodate them on humanitarian grounds leaving the imbroglio to continue. The above discussion does not leave any option but to reiterate a long drawn and emotionally painful strategy which is to repatriate the Afghan refugees to their places of origin. This diverts the discussion towards the problems faced by Afghan refugees when they try to return back to their ancestral lands. 


\section{REFERENCES}

Amnesty International, (2012, June 29), “Afghan refugees face mass deportation from Pakistan," AFP.

BI/NRC (2010), Realizing National Responsibility for the Protection of Internally Displaced Persons in Afghanistan: A Review of Relevant Laws, Policies, and Practices http://www.brookings.edu/ /media/research/files/reports/2010/11/ afghan\%20national\%20responsibility/20110211_afghan_national responsibility.pdf

Fleeing war, finding misery: the plight of internally displaced in Afghanistan,

http://www.amnesty.org/en/library/asset/ASA11/001/2012/en/165 09ae3-8407-4f1a-95e8-029fle08397d/asa110012012en.pdf

Holborn, Louise W. (1956). The International Refugee Organization: a specialized agency of the United Nations, its history and work, 1946-1952. London: Oxford University Press.

Human Rights Watch (2011), "Just Don't Call It a Militia" Impunity, Militias, and the "Afghan Local Police" http://www.hrw.org/sites/default/files/reports/afghanistan0911web wcover.pdf

International Committee of the Red Cross (2009), Afghanistan Opinion Survey \& in-depth research.

http://www.icrc.org/eng/assets/files/2011/afghanistan-opinion-surv ey-2009.pdf

IDMC (2013), Afghanistan: Comprehensive response urgently required as displacement crisis

worsens.http://www.internaldisplacement.org/8025708F004CE90

B/(httpCountrySummaries)/4FF5EA3123CE448DC1257B39005B E6F0?OpenDocument\&count $=10000$

Kalumiya, Kallu (2001), "State sovereignty and protection of refugees and displaced persons" in Stefania Baldini and Guido Ravasi, (Eds.) Humanitarian action and state sovereignty: refugees a continuing challenge, San Remo: International Institute of Humanitarian Law.

Knowles, M. (1992), "Afghanistan: Trends and prospects for refugee repatriation", Washington DC: Refugee Policy Group.

Majidi, Nassim (2011, January 25). Urban Returnees and Internally Displaced Persons in Afghanistan http://www.refugeecooperation.org/publications/Afghanistan/01_ majidi.php

OCHA (2012, December). Helping slum dwellers in Kabul cope with winter http://reliefweb.int/sites/reliefweb.int/files/resources/Humanitarian _Bulletin_Afghanistan_Issue_11-01-31_December_2012.pdf

Oxfam (2012, November). The Cost of War: Afghan Experiences of Conflict, 1979-2009.

http://www.oxfam.org/sites/www.oxfam.org/files/afghanistan-thecost-of-war.pdf

Pulla, V. (2012) Comments on article 'The future of Afghan refugees in Pakistan

http://www.insightonconflict.org/2012/09/afghan-refugees-pakista $\mathrm{n} /$

Rizvi, S. (2011, June 25). Internal Displacement in Afghanistan, Refugee Corporation.http://www.refugeecooperation.org/publicati ons/Afghanistan/08_rizvi.php

Sakreli, Laerte (2013). Internally Displaced Persons: United
Nations Human Rights Committee, Model United Nations Illinois http://www.modelunitednationsillinois.com/back_guide/final/hrc_i dp.pdf

TLO/NRC (2011, December 8). Conflict-induced Internal Displacement in Afghanistan

http://www.internaldisplacement.org/8025708F004CE90B/(httpD ocuments)/9FFD3889096CD1E2C12579DF00307589/\$file/201112-08_NRC-TLO_IDP-Briefing-Note.pdf

United Nations, (1988), Guiding Principles on Internal Displacement, U.N. Doc. E/CN.4/1998/53/Add.2 (1998), noted in Comm. Hum. Rts. res. 1998/50. ( February 1998). University of Minnesota

http://www1.umn.edu/humanrts/instree/GuidingPrinciplesonIntern alDisplacement.htm

UNHCR, Convention and Protocol relating to the Status of Refugees

http://www.gdrc.org/doyourbit/refugee-convention.pdf-(1997),

"The State of the world's refugees: A humanitarian agenda." Oxford University Press: London

http://www.unhcr.org/cgi-bin/texis/vtx/page?page=49e486eb6

(2008, November), National Profile of Internal Displaced Persons (IDPs) in Afghanistan

http://www.unhcr.org/cgi-bin/texis/vtx/page?page=49e486eb 6

(2011). Country Operations Profile, Afghanistan. http://www.unhcr.org/cgi-bin/texis/vtx/page?page=49e486eb 6

-(2012, July) Conflict- Induced Internally Displaced Persons in Afghanistan Interpretation of Data of 31 May 2012 http://afg.humanitarianresponse.info/sites/default/files/UNH CR\%20IDP\%20Report\%202012.pdf

(2013) Afghanistan: 2013 UNHCR country operations profile: http://www.unhcr.org/pages/49e486eb6.html

UN News Centre (2011, November), Afghanistan has 'long way to go' in protecting women from violence - UN report http://www.un.org/apps/news/story.asp?NewsID=40491

UNAMA (2013, February). Afghanistan Annual Report 2012. "Protection of civilians in armed conflict." http://unama.unmission s.org/LinkClick.aspx?fileticket=zYmVmJCwBe4\%3d\&tabid=122 54\&language $=$ en-US

UN High Commissioner for Refugees. (2011, May). Research Study on IDPs in urban settings Afghanistan, http://www.refworld. org/docid/511e51382.html [accessed 16 June 2013]

USAID (2012, December 21). Afghanistan complex emergency Fact Sheet No 1 Fiscal year (fy) 2013

WB/UNHCR (2011, May). Research Study on IDPs in urban settings

http://siteresources.worldbank.org/EXTSOCIALDEVELOPMEN

T/Resources/244362-1265299949041/6766328-1265299960363/

WB-UNHCR-IDP_Full-Report.pdf

World Bank (2012, February), Poverty and food security in Afghanistan, analysis based on the national risk and vulnerability assessment 2007/08 http://moec.gov.af/Content/files/FSR_v7.pdf

Zieck, Marajolene (1997). UNHCR and voluntary repatriation of refugees: A legal analysis. Hague: Martinus Nijhoff Publishers. 